\title{
Outros territórios da música independente brasileira no início do século XXI: uma discussão a partir do catálogo de artistas do rock independente de Teresina (2001-2017)
}

\author{
Thiago Meneses Alves (Universidade do Porto, Porto, Portugal)
}

thiagomeneses85@gmail.com

\begin{abstract}
Resumo: É notório o incremento das pesquisas sobre fenômenos musicais “independentes” na agenda acadêmica brasileira nos últimos anos. No entanto, são ainda poucas as pesquisas que forneçam indicativos sobre o volume de agentes e estruturas atuantes, assim como do material artístico produzido nestes contextos. É relativamente clara, também, a pouca presença, nesta bibliografia, de territórios situados mais distantes dos principais centros econômicos e políticos do Brasil. O artigo busca adentrar nesta dupla lacuna a partir da apresentação e análise de um catálogo de artistas que atuam ou atuaram no rock independente de Teresina, capital do Piauí, nos primeiros anos do século XXI. Antes da análise, são explicados os procedimentos de coletas dos dados e os critérios utilizados para a construção deste arquivo. Verificou-se quer o caráter robusto da produção de rock autoral da cidade, com mais de 150 nomes catalogados, quer a diversidade deste conjunto em termos estéticos, ideológicos e sociodemográficos.
\end{abstract}

Palavras-chave: Música independente; Brasil; Teresina.

Other territories of the independent brazilian music in the early 21st century: a discussion from the catalog of artists of the independent rock of Teresina (2001-2017)

Abstract: It is notorious the increase of the researches about "independent” musical phenomena in the Brazilian academic agenda in the last years. However, there are few works that provide data about the quantity of agents and instances as well as of the artistic material produced in these contexts. It is relatively clear also the weak presence in this bibliography of various territories far away from the main Brazilian economic and political centers. The article aims to discuss this double gap from the presentation and analysis of a catalog of artists that develop or developed activities in the independent rock of Teresina, capital of Piauí State (Brazil), in these first years of the 21st century. Before the analysis, it is explained the data collection procedures and the general criteria that guided the construction of this catalog. It was verified both the robust character of the Teresina's rock production, with more than 150 names catalogued, and the diversity in aesthetic, ideological and sociodemographic terms.

Keywords: Independent music; Brazil; Teresina.

\section{Introdução}

Em linhas gerais, o termo "independente" no âmbito musical é movimentado para designar aquelas produções geradas fora do aparato das grandes indústrias culturais. Historicamente tem sido utilizado no âmbito da indústria fonográfica para demarcar as grandes gravadoras multinacionais e os selos mais especializados, que trabalharam sobretudo as produções negligenciadas por aquelas instâncias (SHUKER, 1998, p. 144-145). Mais do que a oposição irrestrita, a complementaridade tem caracterizado estas relações, com vários exemplos de iniciativas (artísticas, empresariais) cuja gênese se dá no meio independente e que, posteriormente, passam a adotar procedimentos historicamente ligados ao mainstream musical (HESMONDHALGH, 1999, p. 34) ${ }^{1}$.

Mesmo que atualmente já exista um conjunto relevante de pesquisas sobre as diversas facetas do universo musical independente do Brasil, o número de contextos com estas características não contemplados na esfera acadêmica é ainda muito grande. Neste sentido, a premissa já não tão nova de Vaz (1988), contida em uma das primeiras publicações brasileiras sobre a música independente, é ainda bastante atual. Dizia o autor:

Existem outros mundos alternativos dentro do universo alternativo da música independente. E, apesar de não incluídos como pontos de referência desse universo, são corpos que evidenciam a sua densidade e diversidade. Registrá-los é um oportuno e necessário rastreamento. (VAZ, 1988, p. 48). 
Além desta problemática que versa sobre a quantidade de contextos não contemplados, existe outra tão complexa quanto: não raramente, as abordagens acabam por focar aspectos muito específicos - um gênero musical, um espaço de fruição, uma trajetória artística, etc. -, deixando escapar esclarecimentos mais substanciais sobre o volume de agentes e instâncias atuantes, bem como dos produtos artísticos gerados nestes contextos. Ainda que esta opção de recorte de pesquisa mais focalizado não configure o problema em si, a falta de mais empreitadas cujos objetivos passem por catalogações que forneçam indicativos mais substanciais contribui para o desconhecimento quase generalizado sobre estes territórios de produção musical.

No caso específico da produção musical de Teresina, mas certamente de outros contextos similares, o incremento e disseminação das tecnologias de registro e distribuição nos últimos anos permitiu superar um velho gargalo: a materialização em obras de uma criatividade artística em torno da música popular que, no caso da capital piauiense, já era verificada em níveis elevados desde pelo menos meados da década de 1980. Assim, se já era contabilizado um grande número de composições no cenário musical da cidade naquela altura, cujo principal espaço de exposição eram os festivais de música, ${ }^{2}$ o registro fonográfico, por conta do deficit tecnológico, era ainda uma situação excepcional (MEDEIROS, 2013, p.41). Somente a partir de meados dos anos 2000 é que essa lacuna passa a ser parcialmente equilibrada. Não por acaso, período em que começam a ser sentidas grandes mudanças nos modos de produção, distribuição e consumo de música, ${ }^{3}$ possíveis em grande parte graças à emergência do ambiente digital nas sociedades contemporâneas.

Em última análise, o momento atual, ainda que contenha inegáveis desafios para as produções musicais independentes, ${ }^{4}$ fornece também um conjunto substancial de oportunidades. ${ }^{5}$ Estas oportunidades têm permitido a estes territórios musicais atingirem, na esteira do argumento de Pierre Bourdieu (1996, p. 325) sobre os segmentos artísticos relativamente especializados, estágios de (relativa) autonomia e sedimentação. ${ }^{6}$ É neste sentido a importância de mapeamentos que forneçam subsídios para contextualizações mais sólidas. Os catálogos - de agentes, instâncias e produtos - são importantes procedimentos neste sentido.

Este artigo busca contribuir com a discussão destas duas grandes lacunas nas pesquisas sobre a independência musical no contexto brasileiro: (1) a pouca representatividade dos territórios distantes de grandes centros econômicos, políticos e mediáticos do país; (2) a falta de indicativos mais sólidos sobre o volume de agentes, instâncias e produtos verificados nestes contextos musicais.

Para tal empreitada, far-se-á uma apresentação e análise do catálogo de artistas que atuam ou atuaram no rock autoral de Teresina nestes primeiros anos do século XXI. Este material foi reunido e sistematizado no âmbito de um doutorado em sociologia e pode ser consultado nos anexos da tese (ALVES, 2017, p. 431-566). Mesmo após finalizado o doutorado, o catálogo continua a ser atualizado. Para tanto, foi criado o website Arquivo Rock Teresina (https://rockteresina.wixsite.com/arquivo). O site, no ar em caráter experimental, tem por intuito principal a divulgação mais efetiva e simplificada dos resultados da pesquisa. Constitui um banco que fornece uma panorâmica dos artistas e os respectivos produtos gerados no rock independente de Teresina neste início de século XXI, assim como da bibliografia produzida sobre este segmento musical. Antes da apresentação do catálogo de artistas, serão feitas descrições detalhadas das técnicas de recolha de dados utilizados na pesquisa, dos critérios que nortearam a sua construção e dos principais desafios encontrados neste processo. 


\section{Breve apresentação dos procedimentos metodológicos da pesquisa}

O quadro teórico e os procedimentos metodológicos utilizados na pesquisa estão inseridos, respectivamente, no domínio disciplinar da sociologia e no referencial das metodologias qualitativas. Consiste numa atualização de parte do material empírico utilizado em uma tese de doutorado, com a inserção de novos nomes no catálogo de artistas.-

No intuito de promover uma busca organizada e pormenorizada de informações, optou-se pelo estudo de caso único. Este consiste na delimitação de uma unidade de pesquisa bem contextualizada no tempo e no espaço, no intuito de promover a recolha criteriosa de dados (VENTURA, 2007, p. 384). Os contornos deste caso em termos espaciais são a cidade de Teresina e em termos temporais os primeiros anos do século XXI (2001-2017). A recolha de dados, por seu turno, foi operacionalizada a partir de dois procedimentos principais: a coleta documental e a realização de entrevistas semiestruturadas.

A coleta documental consistiu na formação dos seguintes catálogos: (1) os artistas que atuam ou atuaram no rock autoral de Teresina no decorrer do século XXI (2001-2017); (2) as entidades promotoras de eventos; (3) os espaços de fruição; (4) as instâncias de legitimação no âmbito da imprensa; (5) a produção fonográfica; (6) os videoclipes. A formação dos catálogos referentes às instâncias que exercem atividades no rock autoral de Teresina (promotoras de eventos, espaços de fruição e instâncias de legitimação) foi estruturada a partir do acompanhamento sistemático da programação. No caso dos catálogos referentes aos artistas e suas respectivas obras (fonogramas e videoclipes), além do escrutínio das principais plataformas musicais onde estes agentes depositam seus produtos na web, ${ }^{7}$ foram contatados colecionadores, que disponibilizaram rico material para consulta.

Foram realizadas ainda 32 entrevistas semiestruturadas, presenciais ou via recursos eletrônicos (email ou chat), com agentes que exercem ou exerceram variadas funções no rock autoral de Teresina no decorrer do século XXI (músicos, empreendedores culturais, jornalistas, acadêmicos, fãs, gestores públicos, videomakers). ${ }^{8} \mathrm{O}$ conteúdo destas entrevistas foi tratado a partir da metodologia proposta por Isabel Guerra (2006, p.68-87), que consiste nas seguintes fases: (1) transcrição; (2) leitura detalhada; (3) construção de sinopses; (4) análise descritiva; (5) análise interpretativa.

No fim, essa coleta multivariada permitiu a triangulação de dados que possibilitou construir as considerações finais. Nas páginas a seguir são apresentadas algumas atualizações referentes a um destes catálogos: o dos artistas que exercem ou exerceram atividades no rock independente de Teresina no início do século XXI.

3 Os critérios para a construção de um catálogo de artistas do rock independente de Teresina no início do século XXI

Como ressaltado no primeiro tópico, foi verificada uma quantidade relevante de artistas atuando no rock autoral de Teresina nestes primeiros anos do século XXI, cujo catálogo contabilizava 151 projetos musicais até o momento da escrita deste artigo. A diversidade estética é um primeiro ponto que chama a atenção nesta lista. Foram quatro os grupos delineados: rock-pop; indie-rock; híbridos; rock vintage. É relevante também a quantidade de situações excepcionais que, por diferentes motivos, entraram na amostra final, sob a categoria "outros". 


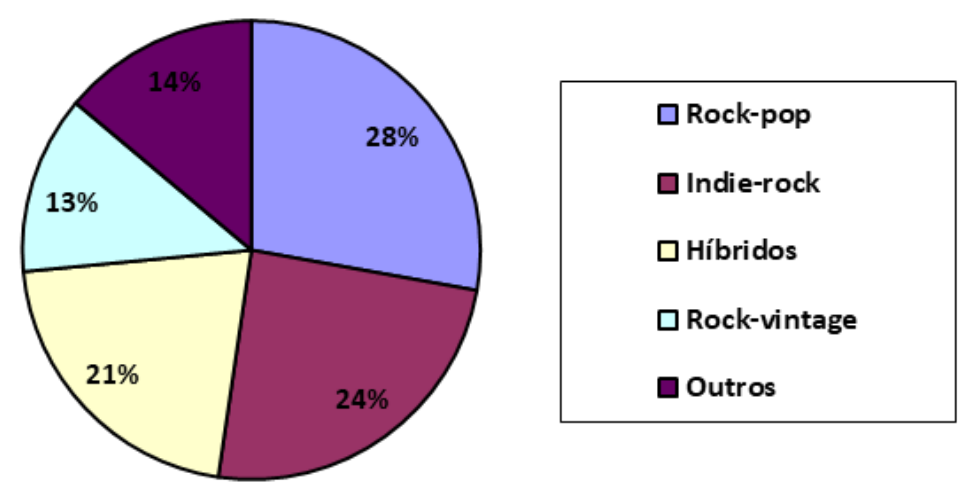

Figura 1: Distribuição dos artistas (bandas e carreiras-solo) que atuam ou atuaram no rock independente de Teresina no início do século XXI (2001-2017).

Fonte: Elaboração própria, ANO.

Os dois critérios gerais que determinaram a inserção no catálogo foram: (1) a configuração da proposta musical dentro de uma estética roqueira; (2) a existência de produtos fonográficos que comprovassem as atividades autorais. Tendo em vista o grande manancial de material verificado nesta fase preliminar, ficou clara a necessidade de diminuir o montante trabalhado. No intuito de promover uma delimitação que não fosse arbitrária, optou-se pela não-inclusão dos segmentos de punk e heavy metal num primeiro momento. ${ }^{9}$ Por configurarem, via de regra, subculturas/agrupamentos urbanos bastante particulares (SILVA; GUERRA, 2015; JANOTTI JR., 2014), estes grupos possuíam as características gerais que permitiam análises individualizadas, portanto, fora do escopo deste arquivo num primeiro estágio. Isso pode ser verificado a partir do escrutínio da programação: geralmente, estes artistas atuam em eventos e espaços bastante específicos, diferentemente do restante da produção roqueira da cidade.

Os outros grupos que constituíram o catálogo desta investigação, por outro lado, apesar das idiossincrasias, sobretudo em termos estéticos, possuíam mais laços comuns: eram mais misturados nos eventos e espaços que tradicionalmente abrem as portas para a produção de música autoral. De toda forma, a construção de um catálogo nestes moldes não intenta, e nem deve, se propor definitiva e/ou totalizante. Em primeiro lugar, em nome da própria operacionalidade da tarefa, que, no caso específico dessa pesquisa, teve que se privar num primeiro momento da inclusão dos segmentos heavy metal e punk. Em segundo lugar, por conta da própria improbabilidade de uma coleta total.

Esta improbabilidade de totalização, o que não significa uma impossibilidade de generalizações científicas, foi verificada neste processo de diversas maneiras. Assim, houve casos de artistas que se declaravam autorais mas dos quais não foram encontrados registros fonográficos. Há também os casos de artistas que estavam em processo de gravação dos seus primeiros registros antes do fechamento parcial para a escrita deste artigo. Numa atualização seguinte do catálogo, uma vez que as obras estejam disponíveis, estes serão inclusos.

Deve-se considerar também que é simplesmente alta a probabilidade de artistas que possuem os requisitos necessários para figurar neste acervo não serem incluídos. Em primeiro lugar, pela rapidez com que surgem e desaparecem bandas neste tipo de contexto, muitas vezes deixando poucos rastros da sua produção. Em segundo lugar, partindo do pressuposto de que nem toda a produção converge para o ambiente digital, principalmente aquela surgida no início dos anos 2000, época em que o acesso à internet e as plataformas de divulgação musicais eram consideravelmente menores. É neste sentido que a triangu- 
lação de dados configurou um procedimento fundamental na montagem deste arquivo: a consciência de que nem toda a informação converge para a internet foi fundamental para considerar, além da documentação disponível nas supracitadas plataformas digitais de música, o trabalho de terreno, feito a partir da realização de entrevistas, cujos agentes não raras vezes contribuíram com material para a montagem do catálogo.

No fim, mais do que uma amostra total e definitiva, o que se intenta com este arquivo é a montagem de um acervo representativo e em contínua construção do rock independente de Teresina. Essa atualização permanente acontece quer em termos retroativos - a descoberta de um artista antigo -, quer em termos sincrônicos - quando da descoberta do surgimento de um novo artista com condições para figurar no catálogo.

A opção por este procedimento de quantificação inicial está ligada sobretudo à condição periférica da cidade. Diferentemente das pesquisas sobre fenômenos musicais independentes localizados em contextos centrais do país, no caso de uma empreitada do gênero em contextos como os da capital do Piauí, o pesquisador se depara com um desafio básico já nas justificativas do projeto: provar, em primeiro lugar, a existência; posteriormente, a dimensão robusta e diversificada; e, consequentemente, a relevância musical da realidade que se propõe a investigar.

Finalizada a primeira etapa (inclusão dos projetos artísticos dentro do catálogo) verificou-se uma grande diversidade. Isso significava a necessidade de organizar o material em categorias a partir de critérios lógicos de classificação. Para nortear este processo, optou-se pela perspectiva dos gêneros musicais (FRITH, 1996; JANOTTI JR., 2003). Além do papel fundamental de músicos, intérpretes, produtores culturais, esta perspectiva pressupõe também o papel ativo dos consumidores, assim como todas as especificidades dos contextos sociais de produção, circulação e consumo, nas classificações e julgamentos musicais.

O caráter distintivo desta perspectiva é que não se parte do pressuposto de que apenas os agentes ligados à produção outorgam significados às categorias musicais, sublinhando-se também o importante papel exercido pelos ouvintes. Portanto, considera as condições de produção, mas, também, de reconhecimento. Assim, o surgimento de um determinado gênero musical, bem como o enquadramento de uma determinada obra sob o seu domínio, deve levar em conta não apenas os aspectos estéticos das canções, mas todo um manancial social e ideológico que orbita em torno destas práticas de julgamento e classificação (JANOTTI JR., 2003). Ou como argumenta Simon Frith (1996, p. 94): “Nós só podemos começar a compreender o sentido da estética da música popular quando nós entendermos, primeiro, a linguagem em que os julgamentos de valor são articulados e expressos e, segundo, as situações sociais em que eles são apropriados".

Os grupos identificados a partir da perspectiva dos gêneros musicais no caso do rock independente de Teresina possuem marcas universais (o rock vintage e o indie rock), nacionais (o rock pop) e locais (o rock regional). Isso demonstra, em primeiro lugar, a grande influência dos fluxos de cultura transnacionais. Demonstra, ao mesmo tempo, a forte dimensão local presente na música popular da capital do Piauí, característica que segue uma lógica já apontada por Holly Kruse (2010) nos seus trabalhos sobre as cenas musicais independentes: apesar da intensa inserção nos fluxos globais, maximizadas pelas ferramentas tecnológicas, a dimensão local destas cenas de música não é apagada. Ao contrário, permanecem como fortes atributos. 


\section{O catálogo de artistas do rock independente de Teresina no início do século XXI}

\section{Rock-pop: a visibilidade no rock teresinense}

Na literatura anglo-saxônica, o binômio rock-pop tem sido movimentado para sublinhar o caráter ambíguo na formatação de um dos mais importantes e influentes gêneros de música popular surgidos na segunda metade do século XX. Por um lado, é marcado por um discurso progressista, historicamente ligado às reivindicações da juventude do pós-guerra (rock). Por outro lado, tem uma vinculação histórica com a indústria fonográfica, um dos mais influentes segmentos da indústria cultural (pop) (FRIEDLANDER, 2002, p. 12).

No Brasil, esse binômio calcado em uma música com estética rock, representativa dos anseios da juventude, de grande visibilidade, teve seu período áureo na década de 1980 (ALEXANDRE, 2002). Apelidado de Brock (DAPIEVE, 1995), este conjunto heterogêneo de trajetórias artísticas teve como mérito literalmente colocar o rock nacional sob os holofotes da grande indústria cultural do país. Naquela altura, estes artistas atingiram algumas das mais importantes instâncias de legitimação no âmbito da música popular: os grandes cadernos culturais, as capas das revistas, as aberturas das novelas, as trilhas sonoras de filmes.

Portanto, o termo rock-pop é movimentado no âmbito desta pesquisa para designar as propostas afinadas com algumas características marcantes também verificadas no Brock. Dos 151 projetos musicais que compõem este catálogo, 42 fazem parte do rock-pop teresinense,${ }^{10}$ configurando $27 \%$ do montante total. Alguns dos trabalhos que mais repercutiram naquele contexto cultural estão inseridos dentro deste grupo. Estes artistas produziram algumas das canções mais conhecidas do repertório autoral da capital do Piauí, como, por exemplo: Trazer você aqui (Amigos do Vigia), Freak Lagarta (Brigite Bardot), Pecado original (Don Corleone), Homem do Amanhã (Mano Crispin), A volta do Zorro (Teófilo), Minas e minas (Edvaldo Nascimento).

Ainda que muitos artistas vinculados ao rock-pop teresinense estivessem bastante afinados também com a prática do cover (a execução de músicas de outros artistas, geralmente famosas), foram fundamentais para o desenvolvimento do cenário autoral roqueiro. Neste sentido, estes artistas desenvolveram também o papel de desbravar espaços importantes a partir da inserção, junto à prática do cover, de músicas próprias em alguns espaços que, gradativamente, começaram a abrir as portas para a música autoral.

No decorrer dos anos 2010 se tem verificado quer a permanência de artistas mais experientes, quer o surgimento de novas carreiras: Flip, In Nature, Dario Marreiros e Taiguara Bruno são alguns bons exemplos neste sentido. Os dois primeiros são parte de uma vertente dentro do rock-pop teresinense que misturou bem as guitarras distorcidas do rock com o reggae. ${ }^{11}$ Os dois últimos nomes compõem a safra mais recente de compositores teresinenses. Enquanto Dario mescla as guitarras do rock com a tradição da MPB, Taiguara possui uma grande influência do Brock, bem como da tradição musical nordestina.

Em um resumo esquemático, as características principais do rock-pop teresinense são: configura o maior grupo dentro do rock independente de Teresina; contém alguns dos nomes que alcançaram maior visibilidade naquele contexto; um dos principais motivos é a maior exposição nas instâncias de legitimação; utilização majoritária da língua portuguesa; o diálogo entre local/global não é tão evidenciado nas formatações sonoras e discursivas, ainda que, ocasionalmente, possa vir a acontecer. 


\section{Indie-rock: a faceta mais alternativa no rock autoral teresinense}

O indie-rock tem suas raízes fincadas no contexto musical britânico de meados da década de 1980. Tinha como concepção ideológica fundamental radicalizar a autonomia dos músicos de rock num âmbito conservador da indústria fonográfica (HESMONDHALGH, 1999, p. 35). As reivindicações dos agentes ligados ao indie extravasaram o âmbito específico daquele gênero musical e configuraram pressupostos importantes do próprio discurso da independência musical britânico. Algumas características que permitem uma determinada comunidade de ouvintes identificar uma proposta artística enquanto indie são: vinculação com selos/gravadoras independentes; não circular nos veículos da grande mídia; utilização maioritária da internet na divulgação dos trabalhos; registros low-fi; utilização de guitarras "sujas” (GUMES, 2012, p. 8).

O surgimento de bandas como Fellini e Maria Angélica não mora mais aqui, assim como de selos como o Madsummer Madness, exerceram um papel fundamental na consolidação desse gênero musical no universo independente do Brasil no final da década de 1980. De um modo geral, estes artistas configuraram um contraponto à produção de rock mainstream, representada pelo Brock (CAMPOS, 2013, p. 5).

Quando se olha para a lista dos artistas que fizeram mais sucesso no rock autoral de Teresina no decorrer do século XXI, pode parecer que não existiu um segmento indie substancial na capital do Piauí. Contudo, no decorrer deste processo de catalogação foram verificados 37 projetos musicais neste grupo, representando cerca de $25 \%$ da amostra total, e configurando o segundo grupo em termos quantitativos. ${ }^{12}$

Neste sentido, não deixa de ser interessante sublinhar o paralelo com o contexto nacional no que toca aos contrastes entre o rock da esfera mainstream e aquele independente. Assim, não obstante as intensas atividades, verificadas no surgimento de um conjunto relevante de artistas autorais, espaços e programações específicas, o reconhecimento desta vertente dentro do conjunto geral da produção de rock da cidade é menor.

Um dos pioneiros acontecimentos do indie teresinense foi o surgimento do grupo Ravena em 1994. Além de lançar um EP chamado Lonely Noise ${ }^{13}$ com qualidade bastante razoável para o material produzido em Teresina na altura, alguns membros formariam posteriormente um dos principais grupos do indie na cidade, o Növa. Ainda nos anos 2000, grupos como Bedtrip Clube, Tequinoisi, Atun e Trinco ajudaram a escrever várias páginas da história deste segmento musical, abrindo portas para uma importante produção que se sedimentaria posteriormente. Neste conjunto, tem importância fundamental o surgimento do Devotchka. Ainda que praticasse o cover, a banda exerceu uma importante função de disseminar um repertório alternativo na capital piauiense. Além disso, vários membros deste projeto seguiriam em bandas autorais posteriormente. Eis mais um motivo para uma problematização menos rígida da relação cover/autoral, mesmo nos segmentos de música independente.

Um dos frutos mais notáveis das atividades desenvolvidas no âmbito do indie teresinense nos anos 2010 é o surgimento do Guardia. Um dos projetos de maior destaque do cenário musical do Piauí nos últimos anos, o duo mescla com desenvoltura as suas referências alternativas com a tradição da MPB, contabilizando dois álbuns em listas de melhores lançamentos nacionais nos anos de 2013 e $2015 .^{14}$

O surgimento, dentro do indie-rock teresinense, do grupo de post-rock Wake Up, Killer, ainda nos anos 2000, configurou um dos pontapés iniciais para o aparecimento de mais bandas dedicadas ao rock instrumental na capital do Piauí: Aloha Haole, Vulgo Garbus e Modstock são alguns dos exemplos recentes mais conhecidos. Uma tendência, inclu- 
sive, do contexto brasileiro mais amplo, cujo um dos principais expoentes é o grupo cuiabano Macaco Bong. Nos últimos anos, a criação de projetos mais alinhados com o experimental (Cigarretes Over) e com a música eletrônica (Perduvoyage) é uma tendência que se desenha de forma cada vez mais forte neste segmento.

\section{Híbridos: a visibilidade com "sabor" nordestino}

No clássico "Culturas Híbridas”, do antropólogo argentino Néstor García Canclini, o termo hibridações culturais é movimentado para designar uma série de fenômenos, dentre os quais, o conjunto de fusões literárias, artísticas e comunicacionais, cada vez mais frequentes nas sociedades contemporâneas. Em linhas gerais, estes consistem na combinação de processos ou estruturas que existiam de formas separadas, cuja fusão forma novos processos ou estruturas (CANCLINI, 2003, p. 19). A tônica deste tipo de fenômeno estaria no embaralhamento entre as tradicionais categorias de cultura historicamente conhecidas como o culto (produção associada à elite cultural e estudada em disciplinas como a história da arte e a literatura); o popular (conhecimentos e práticas associados ao folclore, estudadas sobretudo no âmbito da antropologia); o massivo (o repertório das indústrias culturais, analisados sobretudo no âmbito das ciências da comunicação e semiologia) (CANCLINI, 2003, p. 23).

No caso específico do rock é importante sublinhar que mesmo que sua gênese se tenha dado num ambiente sociocultural anglo-americano, este tem historicamente se desenvolvido em contextos variados de produção musical (BENNETT, 2001, p. 2). Neste sentido, o diálogo permanente entre aquele gênero de música, enquanto referência cultural de um contexto "central", e as músicas dos contextos locais onde ele é apropriado e ressignificado, configuraria uma característica base deste gênero de música (REGEV, 2013, p. 12).

Tendo em vista estas reflexões preliminares passa-se à apresentação e análise do terceiro grupo deste catálogo, os híbridos. Suas obras são caracterizadas pelo diálogo entre o massivo (rock) e gêneros/tradições musicais populares locais (nordestinas) e nacionais (brasileiras). Foram verificados 32 incidências neste sentido, ${ }^{15}$ correspondendo a $21 \%$ do catálogo.

Dentre a miríade de possibilidades possíveis no âmbito das hibridações culturais, uma ficou particularmente marcada no imaginário cultural teresinense, sobretudo nos anos 2000: o rock regional. Alguns dos artistas mais famosos que utilizaram os procedimentos associados a esta vertente foram os grupos Narguilé Hidromecânico, Conjunto Roque Moreira, Validuaté (principalmente no início de carreira), Captamata, Os Caipora, Carnaubanos da Fronteira, assim como os compositores Hernane Felipe e Nando Chá. Mas, no que consistiria essa vertente que reúne alguns dos mais populares artistas do rock autoral da capital do Piauí?

Uma análise mais aprofundada, de cariz musicológico, ${ }^{16}$ foge aos objetivos mais específicos deste texto. Contudo, devido a especificidade e importância desta questão no rock independente de Teresina, faz-se necessária uma contextualização mínima. Em linhas gerais, a possibilidade de identificar certas marcas locais (brasileiras, mas, sobretudo, nordestinas) numa proposta estética de rock é a principal razão para o êxito desta vertente segundo boa parte dos entrevistados nesta pesquisa. Ainda segundo estes agentes, estas seguiam alguns procedimentos mais ou menos estandardizados.

A alternância entre o rock e gêneros locais ou nacionais numa mesma faixa era um deles. A música poderia iniciar de forma mais amena, dentro do esquema associado a um gênero local como o forró, rumo a um refrão explosivo calcado no peso das guitarras do ro- 
ck. O caso das músicas Me abana bem (Validuaté), Crepúsculo (Conjunto Roque Moreira) e Cimento (Captamata) são bons exemplos.

Junto a estes fluxos de explosão/repouso que se alternavam entre estrofes e refrões, outro procedimento muito associado ao rock regional eram as letras que abordavam aspectos muito específicos do imaginário sociocultural de Teresina. Temáticas como o folclore (Cabeça de Cuia/Teófilo), as altas temperaturas (Me abana bem/Validuaté), os espaços populares (Mercado Central/Batuque Elétrico), as personalidades ilustres (Torquatonight/ Os Oliveira) e as bebidas típicas da capital piauiense (Vendedor de Cajuína/ Conjunto Roque Moreira).

A inclusão de gêneros nordestinos permitia uma expressividade corporal (a dança) que funcionava muito bem nos concertos ao vivo, trazendo um público mais amplo do que aquele estritamente "roqueiro". O auge destes eventos cuja programação girava em torno do rock regional em Teresina foi a realização da I Mostra Cumbuca Cultural, no dia 01 de novembro de 2007. A apresentação, que daria origem a um dos primeiros registros em DVD no segmento analisado, contou com quatro dos maiores nomes do rock regional em atividade naquela altura: Validuaté, Roque Moreira, Captamata e Batuque Elétrico.

Se o rock-pop teresinense possui várias intersecções com o Brock quando comparado ao panorama mainstream brasileiro, o rock regional possui várias intersecções com o fenômeno que ficou conhecida por MpopB, um acrônimo para "Música Pop Brasileira" (ABRAMO, 1996, p. 1). O termo foi cunhado para designar a produção nacional da década de 1990 que arquitetou, com forte apelo popular, a tradição musical brasileira com gêneros transnacionais, num leque extenso de propostas estéticas cujos pontos em comum eram as hibridações culturais. Este procedimento foi verificado do heavy metal de exportação (Sepultura, Angra, Viper) ao rock mais popular produzido na altura no Brasil (Raimundos e Nação Zumbi, entre vários outros). Sem contar as várias outras trajetórias artísticas que o país descobria no início dos anos de 1990: de Daniela Mercury ao dance hall do Skank, trespassando também um conjunto variado de bandas que surgiam no underground nacional (ALEXANDRE, 2013, p. 31).

Assim como no caso da variante nacional, que não se resumiu ao diálogo entre rock e elementos estético-discursivos locais, a miríade de propostas verificadas no grupo dos híbridos excede ao grupo específico do rock regional. Portanto, esta vertente foi uma entre tantas formatações musicais glocais em Teresina naquela altura. A ideia de uma diminuição da influência do rock regional nos últimos anos, verificada nas entrevistas, não significa uma diminuição propriamente dita das propostas que buscam manter este diálogo entre rock e aspectos culturais locais. Mais do que isso: nos dias de hoje (2018), em Teresina, este tipo de procedimento ocorre de forma mais difusa. Prova disso é que são várias as novas trajetórias artísticas que têm surgido nos últimos anos dentro do grupo dos híbridos sem necessariamente adotarem os procedimentos associados ao rock regional. Nomes como Bia e os Becks, Ravel Rodrigues, Valciãn Calixto e Eletrique Zamba são alguns dos mais conhecidos.

O grupo Bia e os Becks e o compositor Ravel Rodrigues, por exemplo, marcam-se dentro daquele contexto a partir da construção de propostas baseadas na fusão do rock com gêneros brasileiros como o brega, MPB ou baião. Principalmente o grupo Bia e os Becks é, nos dias de hoje, um dos principais nomes da cena autoral de Teresina. Enquanto o Eletrique Zamba traz um combo de gêneros - rap, jazz, reggae, samba, entre outros -, sendo o rock, mais do que o carro-chefe, mais um elemento na proposta, Valciãn cunhou o termo Axé-Punk para descrever uma sonoridade que articula o peso das guitarras do rock com o ritmo baiano. 
O fato é que ainda há muito a ser pesquisado neste sentido. Não apenas sobre o rock regional, mas, de forma mais ampla, sobre esse tipo de procedimento de hibridação na produção musical de Teresina.

\section{Rock vintage: quando a referência é o retrô}

O menor grupo verificado no rock autoral teresinense é o do rock vintage, com 19 projetos catalogados, ${ }^{17}$ representando $13 \%$ do montante total. Consistem nos projetos musicais cuja sonoridade tem por base os pioneiros cânones do rock, surgidos entre o nascimento do gênero, na metade dos anos de 1950, até meados da década de 1970. Estes são problematizados a partir do termo classic rock, cujas origens remetem às programações de algumas rádios que focavam nestes artistas. Nomes como Beatles, Rolling Stones, Creedence Clearwater Revival, The Who, The Doors são alguns dos mais emblemáticos. O termo tem configurado, ao longo dos anos, uma categoria de marketing sui generis no âmbito da música popular (ver, neste sentido, as prateleiras de lojas de discos) (SHUKER, 1999, p. 248).

Em linhas gerais, o rock vintage é uma das maiores expressões, em Teresina, de uma característica bastante forte da cultura pop: a referência constante ao seu passado (REYNOLDS, 2011). Alguns dos nomes mais importantes desta vertente do rock autoral de Teresina nestes primeiros anos do século XXI foram: o veterano guitarrista André de Sousa, que tocou em vários projetos importantes naquele contexto e nos últimos anos se tem dedicado à carreira-solo; o grupo Os Radiofônicos, que transita na interface entre o rock vintage e o indie rock teresinense, e que possui uma das trajetórias mais duradouras no segmento musical analisado; assim como o grupo Clínica Tobias Blues, cujo papel na disseminação desse gênero musical na capital piauiense foi chave, e cujos frutos evidentes podem ser verificados no aparecimento posterior de grupos de destaque nesta vertente como o BR-316 e o Fronteiras Blues.

Uma das maiores façanhas recentes do rock autoral de Teresina foi alcançada por uma banda do rock vintage. No ano de 2016, foi concedido ao álbum Walking Alone, do grupo Maverick 75, o prêmio de melhor lançamento de rock/blues pela Akademia Music Awar$d s$, importante entidade da indústria fonográfica sediada em Los Angeles.

\section{Outros projetos musicais no rock independente de Teresina}

Alguns projetos musicais que não estão enquadrados nos grupos anteriormente descritos também entraram, por diferentes razões, no catálogo que compõem esta pesquisa. Estes contabilizam 21 nomes, ${ }^{18}$ representando 14\% do conjunto total. As duas características gerais destas exceções são: (1) projetos que não possuem sonoridades com estéticas baseadas maioritariamente no rock mas que circulam ou circularam bem nas instâncias associadas a este gênero em Teresina (festivais e outras programações, espaços de fruição musical e etc.), fazendo parte, no fim, do imaginário roqueiro da cidade; (2) projetos vinculados ao heavy metal e punk cujas atividades obtiveram tamanho destaque naquele cenário que seria contraproducente uma análise como a que é proposta neste trabalho sem a inclusão imediata dos mesmos.

\section{Sobre a necessidade de analisar realidades musicais negligenciadas a partir da construção de catálogos}

Após o trabalho de catalogação dos artistas constatou-se, além da robustez quantitativa, a diversidade do rock independente de Teresina nestes primeiros anos do século XXI. Uma diversidade não apenas em termos estéticos, mas também em termos sociodemográfi- 
cos e ideológicos. Assim, é importante ressaltar, no primeiro caso, que estes artistas atuam em programações distribuídas em todas as zonas de Teresina, constatação essa feita a partir da construção de um catálogo dos espaços de fruição de rock autoral da cidade (ALVES, 2017, p. 277).

A constatação da diversidade ideológica se dá pela multiplicidade de afiliações e posturas verificadas, ainda que estas possuam um ponto em comum: o caráter de oposição às práticas predatórias em muitas ocasiões verificadas no âmbito das grandes indústrias culturais no que toca à uma programação mais representativa da diversidade musical do Brasil, postura essa coincidente com o que Howard S. Becker (1977, p.15) designou enquanto "artista inconformista". Não obstante esta convergência que permite, em última análise, a coesão relativa dos agentes e instâncias que ali atuam, há todo um conjunto de tensões que exprimem os diferentes posicionamentos e posturas perante a arte independente.

O tipo de proposta contida neste artigo aponta para um balanceamento das narrativas mais conhecidas a respeito da produção musical não apenas em Teresina, mas também no Brasil. No primeiro caso, por contrapor uma ideia ainda muito forte no imaginário cultural da capital do Piauí, e que consiste na premissa de que a produção de música da cidade seria caracterizada sobretudo por um marasmo (MEDEIROS, 2013, p. 91), o que significaria, em última análise, o baixo volume de material. Esta narrativa é questionável quando se olha para o repertório já produzido. No segundo caso, por demarcar fenômenos e contextos marginalizados no panorama nacional, espera-se contribuir para uma escrita mais plural e, consequentemente, mais representativa, da diversidade da música produzida no país neste início de século XXI.

Como dito na introdução, este artigo visa contribuir também para a discussão de lacunas nos estudos sobre a independência musical no contexto brasileiro: as poucas abordagens que forneçam pistas do volume de agentes atuantes e do material artístico produzido nestes territórios mais à margem. Ainda que seja verificado um corpo de abordagens a respeito da produção musical independente, estas, na maioria das vezes, se referem muito mais a aspectos específicos - um artista, um espaço de fruição, um gênero, etc. -, se ressentindo de contextualizações mínimas a respeito das próprias dimensões dos contextos locais em que os objetos de pesquisa estão inseridos.

É neste sentido a importância da criação de catálogos de artistas, produtos fonográficos, espaços de fruição, entre outras instâncias importantes destes contextos. Somente com sistematizações desta natureza são possíveis diagnósticos mais substanciais. Além de configurar um procedimento básico de contextualização das realidades que se pesquisa, este tipo de empreitada pode também fornecer importantes indicativos para a formulação de políticas públicas mais afinadas com as demandas destes segmentos culturais.

Obviamente, essa discussão não consiste em uma crítica, a priori, às investigações mais focalizadas. Contudo, a constatação deste quadro de falta de indicadores sugere urgentemente pesquisas que forneçam a possibilidade de generalizações mínimas a respeito destes contextos locais de produção independente. Sobretudo quando os mesmos apresentam volumes de material humano e artístico substanciais, vide o caso do rock independente de Teresina.

\section{Notas}

1 Para uma discussão dos contornos específicos que os discursos da independência musical adquirem no contexto brasileiro conferir Alves (2017, p. 98-106).

2 Alguns dos principais eventos dos anos de 1980 em Teresina foram: Festival de Música Popular Brasileira do Estado do Piauí (FMPBEPI), I Festival de Sanfoneiros do Piauí, Festival do Parque Piauí (FESPAPI), Festival de 
Música do Bairro Buenos Aires (FEMBA), I Encontro de Compositores e Intérpretes do Piauí, Festival de Mùsica Popular do Bairro Bela Vista (FMPBEVI), Festival Setembro Rock, Festival Nordestino de Música Popular (FENEMP-PI), Festival Musical do Bairro Vermelha, Festival Trilance (MEDEIROS, 2013, p. 31).

3 Cujo efeito mais representativo é a obsolescência do modelo clássico que vigorou no século XX, baseado sobretudo na venda de fonogramas em suportes materiais (HERSCHMANN, 2010, p. 62).

4 A concentração dos intermediários na distribuição de fonogramas no ambiente digital, geralmente feita por grandes empresas de tecnologia, é um dos problemas mais graves dos tempos atuais (cf. DE MARCHI, 2011). A visibilidade num contexto de produção cultural altamente volumoso e segmentado, assim como a sustentabilidade financeira do empreendimento artístico autoral também são outros obstáculos frequentemente mencionados pelos agentes entrevistados nesta pesquisa.

5 Estas estão ligadas às possibilidades de apropriação (ALBAGLI; MACIEL, 2011, p. 32; LEMOS, 2004, p. 237) das ferramentas digitais. Diferentemente da inclusão digital, que pressupõe o uso do artefacto tecnológico consoante ao que é previsto pelo produtor, numa adaptação mais verticalizada, a apropriação consiste no uso para fins próprios (ALBAGLI; MACIEL, 2011, p. 32). É neste sentido a existência de uma astúcia dos usos (LEMOS, 2004, p. 238): além do conhecimento técnico, os agentes que se apropriam destes artefatos tecnológicos possuem fins específicos, muitas vezes, à revelia do planejado pelo fabricante.

6 Além da emergência de um conjunto de obras que contenham traços específicos do campo em que foram geradas, alguns indícios que permitem verificar este estado são: o surgimento de instâncias específicas de reprodução (galerias, museus e etc.) assim como de agentes que se ocupam da divulgação e legitimação (críticos, curadores, colecionadores e outros intermediários). Este estado de (relativa) autonomia e especificidade do rock independente de Teresina pode ser verificado: (1) no surgimento de um corpo substancial de obras, seja numa dimensão fonográfica, seja numa dimensão videográfica; (2) no surgimento de um corpo de críticos, curadores e conservadores, atuantes principalmente na imprensa, seja ela oficial, seja alternativa; (3) na existência de um conjunto também substancial de instâncias de exposição e reprodução daquelas obras, quer em espaços específicos de fruição, quer a partir de entidades que produzem eventos dentro daquele segmento, com presença nos âmbitos públicos, privados e do terceiro setor.

7 Plataformas como Spotify, Deezer, Bandcamp, Soundcloud, Palco Mp3, Toque no Brasil e Last FM.

8 É bastante comum neste tipo de segmento cultural que um agente ocupe mais de uma função.

9 Contudo, a coleta referente a estes segmentos já está em andamento.

10 Acesso, Aclive, Alma Roots, Amigos do Vigia, Banjo Kazuia, Boêmios Errantes, Brigite Bardot, Cami Rabêlo, Cochá, Danilo Rudah, Dário Marreiros, Don Corleone, Edvaldo Nascimento, Flip, Full House, Full Reggae, Ico Almendra, In Nature, Karranka, Locomotriz, Machado Jr., Madalena’s Soul, Madame Baterflai, Mano Crispim, Marlon e os Brandos, Martini Cadilac, Mero Homem, Monise Borges, Origem D3mi, Os Ordinários, Outros Versos, Patrola, Planezza, Projeto 28 Dias, Rocksim, Rubens Figueiredo, Sintonizando Sonhos, Taiguara Bruno, Teófilo, Threis, Veia Sônica, Zona de Atrito.

11 Acesso, Alma Roots e Karranka são outros exemplos desta vertente pop-rock-reggae.

12 Aero, Anna Werther, Atun, Audioteipe, Bedtrip Clube, Bill Marte, Canis Vulgaris, Cigarretes Over, Cine Hollywood, Deep Moon, Devotchka, DJ Barão, Duben, Eufrásia, Flores Radioativas, Freitas, Guardia, Hugo dos Santos, Interface, La Folie, Lisbela, Long Tomorrow, Mr. Potato Head, Natea, Nelson Theresa Café, Növa, No Essence, Orquestra Bimotor, Perduvoyage, Soma!, Tequinoise, The Reid, Trinco, Tupi Machine, Ultra Mega Master, Undead Electric Hyena, Wake Up, Killer!

13 Extended Play, formato menor do que o tradicional álbum, com cerca de cinco músicas.

14 No website Embrulhador. Conferir referências.

15 A Sala da Brusca, Ajuntamento Mar e Son, Alcaçuz, Batuque Elétrico, Bia e os Becks, Captamata, Carnaubanos da Fronteira, Conjunto Roque Moreira, Doce de Sal, Eletrique Zamba, Eletrosilva, Estação Gandaia, Eu Capiau, Fabulah, Fragmentos de Metrópole, Gramophone, Hernane Felipe, Lado 2 Estéreo, My Fuá Band, Narguilé Hidromecânico, Nando Chá, Olga e o Mar, Os Caipora, Ravel Rodrigues, Sandro Moura, Sapucaia, Selestinos, Terê Groove, Trincado e a Solução, Valciãn Calixto, Validuaté e Xico Barroso.

16 Uma interessante análise neste sentido sobre o rock regional, a partir da canção Remédio Caseiro, do Narguilé Hidromecânico, é feita por Mário Rodrigues (2014).

17 Albatroz, André de Sousa, Black Ties, BR-316, Bulldog Jack, Capitão Guapo, Carlos Henrique, Caveiras, Cine Rex Brazil, Clínica Tobias Blues, Cojobas, Fronteira Blues, Kids Outta Nowhere, Maverick 75, Modstock, Neanderthais, Rádio Estéril Vinil, Radiofônicos, Sandro Sertão.

18 Aloha Haole, Anno Zero, Bode Preto, Eita Piula, Frank Farias, José Quaresma, Káfila, Megahertz, Os Oliveira, Obtus, Preto Kedé, Q.I. 69, Regaplanta, Roraima, Severo, Skate Aranha, Thiago E, Vênus, Violante, Vulgo Garbus, V-Road.

\section{Referências}

ABRAMO, Bia. Rock Made in Brasil. Teoria e Debate, 1996.

Akademia Music Awards. Disponível em: <https://www.theakademia.com/>. 
ALBAGLI, Sarita; MACIEL, Maria. Lúcia. Informação, poder e política: a partir do sul, para além sul. In: ALBAGLI, Sarita; MACIEL, Maria Lúcia (Ed.). Informação, conhecimento e poder: mudança tecnológica e inovação social. Rio de Janeiro: Garamond, 2011. p. 9-39.

ALEXANDRE, Ricardo. Cheguei Bem a Tempo do Palco Desabar. 50 causos e memórias do rock brasileiro (1993-2008). 1. ed. Porto Alegre: Arquipélago, 2013. 256p.

ALEXANDRE, Ricardo. Dias de Luta. O rock e o Brasil dos anos 80. São Paulo: DBA Dórea Books and Art, 2002. 399p.

ALVES, Thiago. Genealogia, morfologia, dinâmicas e produtos do rock independente de Teresina no início do século XXI. 2017. 566f. Tese (Doutorado) - Universidade do Porto, Porto, 2017.

ALVES, Thiago. Os Festivais de música independente no capitalismo cognitivo: um estudo de caso da Feira da Música de Fortaleza. 2013. 256f. Dissertação (Mestrado) - Escola de Comunicação da Universidade Federal do Rio de Janeiro, Rio de Janeiro, 2013.

Arquivo Rock Teresina. Disponível em: <https://rockteresina.wixsite.com/arquivo>. Acesso em:

BENNETT, Andy. Cultures of Popular Music. 1. ed. Maidenhead: Open University Press, 2001. 194p.

BECKER, Howard. S. Mundos artísticos e tipos sociais. In: VELHO, Gilberto (Ed.). Arte e Sociedade: ensaios de Sociologia da Arte. Rio de Janeiro, Zahar Editores, 1977. p. 9-26.

BOURDIEU, Pierre. As Regras da Arte. Gênese e estrutura do campo literário. 1. ed. São Paulo: Companhia das Letras, 1996. 431p.

CAMPOS, Cynthia. Quando o Indie Começou? Contribuição das Bandas Fellini e Maria Angélica Não Mora Mais Aqui Para a Consolidação do Indie Rock Nacional. In: CONGRESSO INTERNACIONAL DE ESTUDOS DO ROCK, 1., 2013, Cascavel. Anais... Cascavel: Editora, 2013.

CANCLINI, Néstor. Culturas Híbridas: estratégias para entrar e sair da modernidade. São Paulo: Editora da Universidade de São Paulo, 2003.

DAPIEVE, Arthur. BROCK. O rock brasileiro dos anos 80. 5. ed. São Paulo: Editora 34, 1995. 224p.

DE MARCHI, Leonardo. Transformações estruturais da indústria fonográfica no Brasil 19992009: desestruturação no mercado de discos, novas mediações no comércio de fonogramas digitais e consequências para a diversidade cultural no mercado da música. 2011. 289f. Tese (Doutorado) - Escola de Comunicação da Universidade Federal do Rio de Janeiro, Rio de Janeiro, 2011.

FRIEDLANDER, Paul. Rock and Roll. Uma História Social. 1. ed. Rio de Janeiro, São Paulo: Record, 2002. 490p.

FRITH, Simon. Performing Rites. Evaluating Popular Music. 1. ed. Oxford: Oxford University Press, 1996. 352p.

GUERRA, Isabel. Pesquisa Qualitativa e Análise de Conteúdo: sentidos e formas de uso. 1. ed. Cascais: Princípia, 2006. 95p.

GUMES, Nadja. A Música Faz o Seu Gênero: uma análise sobre a importância das rotulações para a compreensão do indie rock como gênero. 2011. 222f. Tese (Doutorado) - Faculdade de Comunicação da Universidade Federal da Bahia, Salvador, 2011.

HERSCHMANN, Micael. Indústria da música em transição. 1. ed. São Paulo: Estação das Letras e Cores, 2010. 179p. 
HESMONDHALGH, David. Indie: the institutional politics and aesthetics of a popular music genre. Cultural Studies, v. 13, n. 1, p. 34-61, 1999.

JANOTTI JR., Jeder. À procura da batida perfeita: a importância do gênero musical para a análise da música popular massiva. ECO-PÓS, v. 6, n. 2, p. 31-46, 2003.

JANOTTI JR., Jeder. Rock me like the devil. A assinatura das cenas musicais e das identidades metálicas. 1. ed. Recife: Livrinho de papel finíssimo, 2014. 150p.

KRUSE, Holly. Local Identity and Independent Music Scenes, On line and Off. Popular Music and Society, v. 33, n. 5, p. 625-639, 2010.

LEMOS, André. Cibercultura. Tecnologia e vida social na cultura contemporânea. 1. ed. Porto Alegre: Editora Sulina, 2004. 295p.

Lista Embrulhador 2013. Disponível em: <http://www.melhoresdamusicabrasileira.com. br/2013/12/2013.html>. Acesso em:

Lista Embrulhador 2015. Disponível em: <http://www.melhoresdamusicabrasileira.com. br/2015/12/2015.html>. Acesso em:

MEDEIROS, Hermano. Acordes na cidade: música popular em Teresina nos anos 1980. 2013. 131f. Dissertação (Mestrado) - Centro de Ciências Humanas e Letras da Universidade Federal do Piauí, Teresina, 2013.

REGEV, Motti. Pop-rock music: aesthetic cosmopolitanism in late modernity. 1. ed. Cambridge: Polity Press, 2013. 208p.

REYNOLDS, S. Retromania: Pop Culture's Addiction to its Own Past. 1. ed. London: Faber \& Faber, 2011. 496p.

RODRIGUES, Mário. Hibridações musicais de Narguilé Hidromecânico: um estudo de caso sobre a canção Remédio Caseiro. 2014. 63f. Monografia(Graduação em artes) - Departamento de Artes da Universidade Federal do Piauí, Teresina, 2014.

SHUKER, Roy. Popular music. The key concepts. 1. ed. Manchester, Nova Iorque: Routledge Taylor \& Francis Group, 1998. 324p.

SILVA, Augusto; GUERRA, Paula. As palavras do punk. Uma viagem fora dos trilhos pelo Portugal contemporâneo. 1. ed. Lisboa: Alêtheia, 2015.

VAZ, Gil. História da música independente. 1. ed. São Paulo: Brasiliense, 1988. 65p.

VENTURA, Magda. O Estudo de Caso como Modalidade de Pesquisa. Revista Socerj, v. 20, n. 5, p. 383-386, 2007.

\section{Páginas dos artistas}

Amigos do Vigia. Disponível em: <https://www.facebook.com/amigosdovigia/>.

Atun. Disponível em: < http://alandouglasms.tnb.art.br/>. Acesso em:

Aloha Haole. Disponível em: <https://soundcloud.com/alohahaoleband>.

André de Sousa. Disponível em: <https://soundcloud.com/andre-de-sousa >.

Anno Zero. Disponível em: <http://www.annozero.com.br/>.

Brigite Bardot. Disponível em: <https://www.youtube.com/watch?v=tT8oIUnbbvQ>. 
Bedtrip Clube. Disponível em: <http://www.agendathe.com.br/2010/09/downloadeando-bedtrip-clube.html>.

Batuque Elétrico. Disponível em: <http://tnb.art.br/rede/batuqueeletrico>.

Bia e os Becks. Disponível em: <https://soundcloud.com/biaeosbecks>.

Black Ties. Disponível em: <https://www.oitomeia.com.br/entretenimento/musica/2017/07/06/ banda-black-ties-conquista-publico-nacional-e-e-uma-das-atracoes-no-b-b-rock-theresina/>.

Bode Preto. Disponível em: <http://www.bodepreto.com/release.php>.

BR-316. Disponível em: <https://soundcloud.com/b-r-316>.

Cigarretes Over. Disponível em: <https://cigarettesover.bandcamp.com/>.

Conjunto Roque Moreira. Disponível em: <http://roquemoreira.tnb.art.br/>.

Captamata. Disponível em: <https://www.youtube.com/watch?v=RN42B4LpJbY>.

Carnaubanos da Fronteira. Disponível em: <http://nb.art.br/rede/carnaubanosdafronteira>.

Clínica Tobias Blues. Disponível em: <https://soundcloud.com/clinicatobiasblues>.

Dario Marreiros. Disponível em: < http://tnb.art.br/rede/dariomarreiros>.

Don Corleone. Disponível em: <http://www.diariodopovo-pi.com.br/VerNoticia.aspx?id=6720>.

Edvaldo Nascimento. Disponível em: <http://www.tratore.com.br/um_artista.php?id=23143>.

Eletrique Zamba. Disponível em: <https://soundcloud.com/eletrique-zamba>.

Êita Piula. Disponível em: <http://bandaeitapiula.blogspot.pt/>.

Flip. Disponível em: <https://soundcloud.com/fliprrr>.

Fronteiras Blues. Disponível em: <http://tnb.art.br/rede/fronteirasblues>.

Guardia. Disponível em: < http://www.guardia.net.br/discografia.html>.

Hernane Felipe. Disponível em: <http://tnb.art.br/rede/hernanefelipe>.

Hugo dos Santos. Disponível em: <https:/hugodossantos.bandcamp.com/releases>.

In Nature. Disponível em: <https://soundcloud.com/innaturethe>.

Kids Outta Nowhere. Disponível em: <https://www.facebook.com/kidsouttanowhere/>.

Kafila. Disponível em: <http://kafila.tripod.com/>.

Mano Crispin. Disponível em: <http://www.last.fm/pt/music/Mano+Crispin/+wiki>.

Maverick 75. Disponível em: <http://nb.art.br/rede/maverick75>.

Modstock. Disponível em: <https://soundcloud.com/sandro-sertao-1>.

Megahertz. Disponível em: <http://www.tnb.art.br/rede/megahertz>.

Nelson Theresa Café. Disponível em: <https://www.palcomp3.com/ntcafe/>.

Narguilé Hidromecânico. Disponível em: <http://tnb.art.br/rede/narguilehidromecanico>.

Nando Chá. Disponível em: <http://www.last.fm/pt/music/Nando+Ch\%C3\%A1>. 
Os Caipora. Disponível em: <http://oscaipora.blogspot.pt/>.

Os Oliveira. Disponível em: <http://www.last.fm/pt/music/Os+Oliv\%C3\%AAra/+wiki>.

Os Radiofônicos. Disponível em: <http://osradiofonicos.com.br/>.

Obtus. Disponível em: <http://obtus.tripod.com/>.

Perduvoyage. Disponível em: <https://soundcloud.com/perduvoyage>.

Ravel Rodrigues. Disponível em: <https://soundcloud.com/ravel-rodrigues>.

Teófilo. Disponível em: <http://www.teofilolima.com.br/>.

Taiguara Bruno. Disponível em: <https://soundcloud.com/taiguara-bruno>.

Trinco. Disponível em: < http://www.last.fm/pt/music/Trinco/+wiki>.

Thiago E. Disponível em: <https://soundcloud.com/thiagoe>.

Vulgo Garbus. Disponível em: <https://soundcloud.com/vulgo-garbus>.

Valciãn Calixto. Disponível em: <http://www.valciancalixto.com.br/>.

Validuaté. Disponível em: <https://soundcloud.com/validuat-teresina>.

Violante. Disponível em: <https://soundcloud.com/violante_grupo>.

V-Road. Disponível em: <http://v-road.tnb.art.br/>.

Wake Up, Killer. Disponível em: <http://nb.art.br/rede/wuk>.

Thiago Meneses Alves: Doutor em Sociologia pela Universidade do Porto (2017). Mestre em Comunicação e Cultura pela Escola de Comunicação da Universidade Federal do Rio de Janeiro (ECO-UFRJ) (2013) e graduado em Comunicação Social/habilitação em Jornalismo pela Universidade Federal do Piauí (UFPI) (2008). Possui trabalhos centrados na abordagem da música popular e inseridos nos domínios da Comunicação e da Sociologia. Possui experiência no mercado de comunicação do Piauí, tendo atuado nas áreas de webjornalismo e assessoria de imprensa (2007-2010). Atuou também no movimento cultural do Piaú́, nomeadamente no âmbito da circulação e promoção de novos artistas (música) naquele estado (2012-2013). 